\title{
DESIGUALDADES BRASILEIRAS NOS ANOS 2000: UMA ABORDAGEM MULTIDIMENSIONAL
}

Cassiano José Bezerra Marques Trovão ${ }^{1}$ Juliana Bacelar de Araújo²

Resumo: O objetivo deste ensaio é abordar o tema da desigualdade a partir da constatação da necessidade de uma análise multidimensional, apresentando as principais transformações captadas pelos Censos Demográficos de 2000 e 2010 no Brasil e evidenciando alguns avanços e os limites do processo de queda da desigualdade. Os dados apontam que entre 2000 e 2010, houve uma redução da desigualdade de renda corrente na sociedade brasileira. Sob a ótica multidimensional, alguma melhora nos indicadores socioeconômicos também pôde ser observada para além da dimensão econômica da renda monetária, sem que isso, na realidade, tenha representado uma transformação mais profunda do conjunto de insuficiências que atinge e diferencia os diversos estratos dessa sociedade.

Palavras-chave: Desigualdade multidimensional. Desigualdade de renda. Brasil. Censos Demográficos.

\section{BRAZILIAN INEQUALITIES IN THE 2000's: A MULTIDIMENSIONAL APPROACH}

Abstract: The goal of this article is to approach the inequality phenomenum by stating the necessity of a multidimensional analysis, presenting the main transformations captured by the Demographic Censuses of 2000 and 2010 in Brazil, and showing some advances and limits of the process of decay in inequality. The data show that between 2000 and 2010 , there was a reduction of current income inequality in Brazilian society. From the multidimensional point of view, some improvement in socioeconomic indicators could also be observed to beyond the economic dimension (monetary income), but this has not actually represented a deeper transformation of the set of dimensions that differentiates the strata of Brazilian society.

Keywords: Multidimensional inequality. Income inequality. Brazil. Demographic Censuses.

\section{DESIGUALDADES BRASILEÑAS EN LOS AÑOS 2000: UN ENFOQUE MULTIDIMENSIONAL}

Resumen: El objetivo de este ensayo es abordar el tema de la desigualdad a partir de un análisis multidimensional y presentar las principales transformaciones captadas por los Censos Demográficos de 2000 y 2010 en Brasil, evidenciando avances y límites del proceso de reducción de la desigualdad. Los datos apuntan que entre 2000 y 2010, hubo una disminución de la desigualdad de ingressos corriente en la sociedad brasileña. Desde una óptica multidimensional, alguna mejora en los indicadores socioeconómicos también pudo ser observada más allá de la dimensión económica (renta monetária), sin que ello, en realidad, haya representado una transformación

\footnotetext{
1 Universidade Federal do Rio Grande do Norte, Departamento de Economia, Natal, Brasil, c_trovao@yahoo.com.br, https://orcid.org/0000-0002-0292-5651

2 Universidade Federal do Rio Grande do Norte, Departamento de Economia, Natal, Brasil, julianabacelararaujo@gmail.com, https://orcid.org/0000-0002-0523-4231
} 
profunda del conjunto de insuficiencias que alcanza y diferencia a los diversos estratos de la sociedad brasileña.

Palabras clave: Desigualdad multidimensional. Desigualdad de ingresos. Brasil. Censos Demográficos.

\section{Introdução}

A complexidade do tema da desigualdade exige uma análise abrangente que supere os limites das abordagens restritas à distribuição da renda monetária. As heranças históricas que conformaram a sociedade brasileira são evidentemente o ponto de partida para se entender o quadro desenhado no Brasil da década de 2000.

Segundo Dedecca (2010), restrições estruturais e conjunturais, sejam elas de origem econômica, social ou política, tendem a condicionar a evolução das desigualdades existentes no Brasil. As abordagens sobre esse tema devem considerar tanto os desafios do presente e do futuro quanto os constrangimentos herdados de seu passado. Mais que isso, o tratamento deve partir do entendimento de que a desigualdade é um fenômeno complexo, pois se manifesta em diversas dimensões, estrutural, porque é imanente à forma de organização social capitalista, dinâmico, pois em seu processo novas desigualdades passam a conviver com formas já enraizadas, e cumulativo, porque o surgimento de novas desigualdades não implica em substituição e sim em sobreposição de dimensões.

O debate sobre as origens do elevado nível de desigualdade no Brasil parte da formação e constituição do mercado de trabalho livre, na segunda metade do Século XIX, após a proibição do tráfico negreiro, da libertação dos filhos dos escravos com a Lei do Ventre Livre e, finalmente, com o término da escravidão em 1888. O caso brasileiro é bastante particular por conta da não promoção da reforma agrária após a abolição do trabalho escravo.

A regulação pelo Estado do acesso à terra (Lei de Terras) ${ }^{3}$ permitiu a manutenção da estrutura fundiária baseada na grande propriedade privada e impediu, no momento da transição ao trabalho livre, que a população tivesse acesso à terra, o

\footnotetext{
${ }^{3}$ Lei no 601 de 18 de setembro de 1850.
} 
que a obrigou a se subordinar ao trabalho no latifúndio (oriundo do ciclo da cana). A ocupação dessas terras ocorreu por um movimento de expansão da fronteira agrícola que, na ausência de uma reforma agrária, impunha àqueles que as ocupavam, além da falta de respaldo do Estado, a impossibilidade de se estabelecer e de sustentar a pressão dos grandes proprietários, que terminavam por expulsar seus ocupantes. Dessa forma, a regulação da propriedade privada da terra impossibilitou o acesso aos trabalhadores livres (em sua maioria negros), deixando para esses apenas a possibilidade de subordinação do trabalho, sem a detenção dos meios de produção (DEDECCA, 2005, p. 95).

A expansão da fronteira agrícola criou um quadro de desigualdade associada ao estoque de mão de obra, que, após os ciclos do ouro e da cana, deixou de ser utilizada na emergência do novo complexo produtivo do país, o complexo cafeeiro. A formação do mercado de trabalho assalariado foi ainda mais desfavorável à estrutura do mercado de trabalho nascente pela decisão em favor de uma política migratória internacional (Itália, Espanha, Alemanha e Japão), orientada e financiada pelo Estado, em detrimento da possibilidade de se mobilizar internamente o excedente de mão de obra negra livre.

De modo geral, a não utilização da população negra livre contribuiu para a formação e a constituição de um mercado de trabalho que se caracterizaria pela recorrência de um excedente de força de trabalho, o que marcaria o desenvolvimento brasileiro ao longo do Século XX.

Em termos de desigualdade, no início do processo de constituição do mercado de trabalho livre no Brasil estão presentes alguns elementos que compõem o complexo quadro de diferenças entre classes, grupos sociais e indivíduos como: 1) a distinção entre possuidores e não possuidores de propriedade privada da terra; 2) a distinção entre possuidores e não possuidores de meios de produção; e 3) trabalhadores brancos e negros.

Esse mercado de trabalho nascente passou a contar com alguma regulação pública apenas a partir de 1926 com da Emenda no 29 à Constituição de 1891. Segundo Barbosa (2003), essa Emenda concedia ao Congresso Nacional o direito de legislar sobre o trabalho. Esse passaria a ser o mediador dos conflitos de classes, 
enfrentando a questão social no âmbito do mercado de trabalho. Para o autor, essa medida prepararia o terreno para a legislação social, o que revelaria, não apenas o término do isolamento da classe trabalhadora, mas a sua capacidade de vocalizar suas demandas.

Essa regulação se depararia com o início de uma integração entre as atividades econômicas e o mercado de trabalho, num ambiente econômico desfavorável, após o colapso do complexo exportador cafeeiro e da grande Crise de 1929. O quadro econômico desfavorável acabou por estimular o desenvolvimento da indústria doméstica em função das restrições para a importação. ${ }^{4} \mathrm{O}$ início da integração nacional propiciou a quebra da situação de isolamento dos mercados regionais, permitindo o início da mobilização dos trabalhadores nordestinos em direção ao processo de industrialização concentrado na Região Sudeste, em especial no Estado de São Paulo. ${ }^{5}$

Apesar da elevada capacidade de geração de empregos nas atividades urbanas, industriais ou não, no início do processo de integração e constituição da indústria nacional, o problema da absorção de mão de obra amplamente disponível, especialmente no Nordeste, não pôde ser solucionado. A industrialização no Brasil foi um processo em que se verificou uma recorrência de excedentes de mão de obra. Para Dedecca (2010), a evolução da população ocupada, entre 1940 e 1990, foi marcada, apesar do crescimento elevado da ocupação em atividades industriais e nos serviços governamentais e de utilidade pública, por uma reprodução do estoque de ocupados em atividades agrícolas e, principalmente, pelo crescimento expressivo de trabalhadores informais ou em atividades de subsistência.

O processo de industrialização evoluiu sob um modelo político de regulação que reproduziu um mercado de trabalho caracterizado por uma baixa efetividade da proteção social. Para Dedecca (2005), no período de 1940 a 1942, foi estabelecida de forma ampla uma regulação do mercado e das relações de trabalho, a partir da instituição do salário mínimo e a legislação para a regulação das relações de trabalho no âmbito da Consolidação das Leis do Trabalho (CLT), o que possibilitou a organização sindical consentida pelo Estado. Essas leis se destinavam ao mercado de trabalho não agrícola, em um contexto em que a maioria da força de trabalho estava ligada a atividades agropecuárias. Segundo o autor, a baixa efetividade da proteção social decorreu das próprias características da CLT e das restrições ao

\footnotetext{
${ }^{4}$ Ver Furtado (1959) e Oliveira (1975).

5 Ver Cano (1985).
} 
desenvolvimento das relações de trabalho. A instituição do piso mínimo legal da remuneração do mercado de trabalho e o estabelecimento de alguns elementos de seguridade social não foram acompanhados da criação de mecanismos que garantissem que as conquistas se transformassem em regulação efetiva das relações de trabalho nem da difusão do modelo a todos os contratos de trabalho. Somado a isso, o Estado brasileiro, de forma autoritária, não possibilitou à ação sindical o estabelecimento de uma forma autônoma de negociação coletiva que favorecesse essa difusão de direitos.

A recorrência de governos autoritários, que combateram violentamente a ação sindical e o desejo de efetivação de uma regulação social, produziu um cenário que foi agravado pela excessiva disponibilidade de força de trabalho. Essa, por sua vez, dificultou uma organização sindical mais forte, que garantisse melhores salários no processo de industrialização. O baixo grau de proteção social permitiu a reprodução de um mercado de trabalho pouco institucionalizado, onde se verificou a presença marcante de contratos de trabalho estabelecidos na informalidade. Para além do desemprego, constituído pelo excesso de oferta de mão de obra, a informalidade fezse presente como marca do quadro de elevada desigualdade de renda corrente, que se verificou ao longo da trajetória e da formação socioeconômica no Brasil (Baltar e Proni, 1996; Barbosa, 2003; Dedecca, 2005).

A importância do mercado de trabalho para a redução da desigualdade em sua dimensão econômica foi diminuída. O contexto de formação desse mercado permitiu a perpetuação da desigualdade. Verificou-se, assim, um processo que ficou marcado por uma oferta de trabalho que se encontrava à frente da demanda, por uma desorganização do mercado de trabalho em termos de luta (repressão ao movimento sindical) e de organização política (elevado contingente de mão de obra dificultando a organização), além de um Estado que criou uma legislação (CLT) sem usar seu poder para efetivá-la.

Como resultado, observou-se um descasamento entre desenvolvimento econômico (elevado) e desenvolvimento social (baixo). Para Dedecca (2010), a origem desse descompasso está no modelo de regulação que se mostrava virtuoso ao regime econômico, mas que não permitiu o estabelecimento de instituições 
tradicionais de redistribuição de renda relacionadas ao mercado de trabalho e à política social. O processo que combinou desenvolvimento econômico sem desenvolvimento social foi alvo de grande debate nos anos 1970. Diferentes estudos debateram os fatores determinantes da desigualdade de um padrão de crescimento que se processava por uma expansão acentuada da produção, com elevação dos níveis de concentração de renda. ${ }^{6}$

O ciclo de crescimento brasileiro foi interrompido no início dos anos 1980. Nessa década, a sociedade brasileira conheceu um período de dificuldades econômicas oriundas do baixo dinamismo, da elevada inflação e de um contexto internacional desfavorável em termos de financiamento, fluxo de capitais e difusão tecnológica em direção aos países periféricos. A interrupção do crescimento somada à crise da dívida, em um contexto internacional desfavorável, provocou uma queda da Produção Industrial que derrubou o emprego na indústria nas mesmas proporções. Houve forte crescimento da informalidade e do desemprego, inclusive na indústria de transformação. Mas, mesmo com todas essas dificuldades, o país caminhou para a construção e a consolidação de sua democracia. ${ }^{7}$

A Constituição de 1988 garantiu as condições político-democráticas para a promoção de eleições diretas de governantes e representantes políticos em todos os níveis de governo, para a representação e negociação coletiva e para a adoção de políticas sociais universais, em especial de saúde e educação.

No entanto, a primeira eleição direta para a presidência da República, em 1989, foi dominada por um debate sobre o marco regulatório político, econômico e social aprovado no ano anterior. O resultado foi a eleição de um novo governo, cujas propostas eram: abrir a economia em termos comerciais, produtivos, financeiros e tecnológicos; realizar uma ampla privatização das empresas estatais e viabilizar a flexibilidade do sistema de proteção do trabalho e social. Essas propostas partiam do princípio do Estado mínimo, chocando-se radicalmente com as propostas da sociedade brasileira presentes no texto da nova Constituição.

Nos primeiros anos da década de 1990, a execução de grande parte dessas medidas, como a abertura econômica em um ambiente de estagnação com elevada e crescente inflação, traduziu-se em elevado desemprego, desvalorização dos salários

\footnotetext{
${ }^{6}$ Sobre o debate sobre a concentração de renda nos anos 1970, ver Langoni (1973), Malan (1978), Hoffmann (1978) e Serra (1978). Para mais detalhes sobre o processo de industrialização e o regime de salários no Brasil dos anos 1960 e 1970, ver Medeiros (1993).

7 Ver Sabóia (1986).
} 
e corrosão das políticas sociais, alavancadas pelos efeitos perversos no âmbito da desorganização do Estado.

A estabilização inflacionária, após o Plano Real (1994), alcançada no contexto da promoção das aberturas comercial e financeira, foi fortalecida pela atração de capitais a partir do programa de privatização e da adoção de uma política monetária contracionista centrada em juros reais elevados. Isso proporcionou uma reorganização produtiva industrial, cujas consequências foram a queda expressiva da produção e do emprego industriais, a adoção de mecanismos de controle do orçamento público em razão do fim do imposto inflacionário, a destruição de empregos formais, o aumento da informalidade, a elevação do desemprego aberto e a queda dos salários. ${ }^{8}$ Para Dedecca (2010), os efeitos negativos da estabilização foram contidos pela elevação substantiva do salário mínimo em 1995 e sua valorização, ainda que em ritmo menor, nos anos subsequentes.

Entretanto, após duas décadas de baixo crescimento econômico, o início do século XXI permitiu ao Brasil reconquistar uma trajetória de crescimento com geração de empregos, mesmo com a sua interrupção a partir do último trimestre de 2008, quando eclodiu uma crise internacional de grandes proporções. As especificidades econômicas e políticas da década de 2000 trouxeram resultados favoráveis à redução da desigualdade de renda corrente.

Evidentemente, o passado agrário exportador, a formação do mercado de trabalho livre e a não realização de reformas agrárias condicionaram, em parte, a estrutura desigual da sociedade brasileira. No entanto, como se apontou inicialmente, esse fenômeno é bastante complexo e suas diversas dimensões para além daquela associada a fatores econômicos também surgem como elementos definidores dessa estrutura. Apesar de não terem sido apontadas explicitamente as raízes da desigualdade em sua dimensão social, ela pode ser bastante apreendida como parte do processo de formação da sociedade brasileira, em que se observa uma grande carência em termos de investimentos em bens e serviços públicos, e ser explicitada pelos diversos indicadores que serão apresentados na quinta seção deste trabalho.

Assim, para avançar sobre o estudo da desigualdade na sociedade brasileira na primeira década do século XXI e ampliar a análise para além de sua dimensão econômica, é necessário que se compreenda esse processo, de forma um pouco mais profunda, levando-se em conta seus avanços e limites.

\footnotetext{
8 Para uma visão sobre o mercado de trabalho no Brasil e na América Latina dos anos 1990, especialmente quanto ao crescimento da informalidade, ver Cacciamali (2001).
} 
O artigo divide-se em cinco seções, além desta introdução. A primeira procura situar metodologicamente o tema da desigualdade. A segunda apresenta algumas evidências da retomada da atividade econômica dos anos 2000 para a criação de um ambiente favorável à redução das desigualdades. A terceira tem por objetivo apresentar algumas evidências, a partir de interpretações sobre o tema, além de indicar os principais resultados e avanços do processo recente da queda da desigualdade no Brasil. A quarta evidencia os principais limites do processo e traz uma abordagem sobre o tema da desigualdade a partir de uma ótica multidimensional, buscando contemplar em parte a complexidade que este tema possui. Por fim, na última seção, algumas considerações finais intentam elucidar os principais desafios para se alterar estruturalmente a condição histórica de elevada desigualdade no Brasil.

\section{Uma perspectiva metodológica sobre o tema da desigualdade}

Antes de iniciar a abordagem sob o processo mais recente de queda da desigualdade, faz-se necessário situar metodologicamente esse objeto tão complexo. Nesse sentido, o primeiro passo é conceituar uma das muitas dimensões que esse fenômeno possui, aquela de cunho econômico associada à renda monetária. Para tanto, é necessário definir os conceitos de distribuição pessoal e funcional da renda.

O primeiro refere-se à apropriação da renda disponível por parte das pessoas. Normalmente, a informação disponível nos levantamentos domiciliares permite captar as rendas auferidas por meio do trabalho (salário, ordenado, remuneração do trabalho autônomo e pró-labore), do sistema de proteção social (aposentadoria, pensão, auxílios e transferências sociais de renda) e da propriedade de ativos (juros e aluguéis). A abrangência dessa forma de mensuração da renda é relativamente limitada, em razão dela captar, fundamentalmente, a renda corrente declarada pelas pessoas.

Em geral, a declaração de renda pessoal não informa rendimentos obtidos na forma de valorização de ações e títulos, rendimentos de aplicações financeiras e lucros retidos derivados de participação societária. Também não são captados os 
rendimentos não monetários, como subsídio, alimentação, planos de saúde e previdência pagos pelas empresas, utilização de automóveis cedidos pelas mesmas, bem como os gastos com gasolina e manutenção que dos mesmos decorrem.

O segundo conceito foca a estrutura de apropriação da renda em uma abordagem institucional, também denominada de apropriação primária de renda. $\mathrm{A}$ distribuição é analisada a partir das três principais formas de apropriação da renda disponível em um determinado país: (i) excedente operacional bruto das empresas, (ii) remuneração do trabalho e (iii) impostos e contribuições sociais. Para a contabilidade da renda disponível é deduzida a renda enviada ao exterior, inclusive aquela realizada via importação, e adicionada à recebida do exterior, incluída aquela de exportação. A distribuição funcional é construída, portanto, a partir de uma das óticas de mensuração do Produto Interno Bruto, devendo captar todas as formas de apropriação de renda, seja pelas pessoas, empresas ou famílias.

Deve ficar claro que tanto o conceito de distribuição pessoal quanto o funcional da renda contemplam apenas uma dimensão da desigualdade, mais precisamente, aquela associada à sua natureza econômica. Grande parte do debate sobre a evolução da desigualdade no Brasil está circunscrita a essa dimensão econômica.

No entanto, outras dimensões que não aparecem no debate ficam relegadas a segundo plano na grande maioria desses estudos. ${ }^{9}$ Boa parte dessas outras dimensões estão associadas a um conjunto de necessidades sociais que não podem, ou dificilmente, são atendidas pela via monetária ou, mais precisamente, por sua aquisição no âmbito do mercado. Isto significa que, para grande parcela da população, o acesso à renda não necessariamente garantirá a superação de sua condição desigual.

Em outras palavras, a dimensão social, que contempla o acesso a diversos bens públicos como saúde, educação, transporte, água, energia, lazer, saneamento básico, dentre outros, parece ficar de fora do debate. É nesse sentido que este ensaio propõe uma abordagem multidimensional da desigualdade, sem a pretensão de esgotar o tema, mas de forma a contemplar minimamente sua complexidade. Para isso, o próximo passo é analisar a evolução econômica recente, apontando seus efeitos sobre a tendência recente de redução das desigualdades, bem como seus limites.

\footnotetext{
${ }^{9}$ Para acompanhar o debate (nacional e internacional) acerca da mensuração da desigualdade sob uma ótica multidimensional, ver Trovão (2015).
} 


\section{O Brasil dos anos 2000: um ambiente favorável à redução da desigualdade de renda}

No âmbito macroeconômico, a análise da evolução do PIB na primeira década do século XXI, a partir dos determinantes da demanda agregada, permite constatar uma mudança importante no padrão de crescimento da economia brasileira. Esse novo padrão trouxe resultados importantes para a sociedade, impactando positivamente a situação de grande parcela da população que se encontrava nos estratos inferiores da distribuição da renda.

O período de crescimento econômico dos anos 2000 pode ser dividido em quatro: o primeiro, de 2000 a 2004, pode ser caracterizado pelo aumento das exportações, alavancadas pelas desvalorizações cambiais de 1999 e 2002, pelo aumento da demanda internacional, com destaque para o efeito China, e pela melhoria nos preços internacionais das commodities.

O segundo, de 2005 ao final de 2008, representa uma alteração no ritmo e no padrão de crescimento, em que o mercado interno assume um papel importante como fonte dinamismo, especialmente devido à ampliação do consumo das famílias e, principalmente, pela recuperação dos investimentos (FBCF), este último especificamente após 2006.

O terceiro período, que se estende do último trimestre de 2008 ao final de 2009 , foi marcado pelos desdobramentos da crise internacional com forte redução dos investimentos, das exportações e da atividade industrial, decorrentes do contexto internacional de elevada incerteza.

Por fim, no ano de 2010 houve um movimento em direção à recuperação da atividade econômica, com crescimento de 7,5\%, em que se destacam a elevação dos investimentos $(21,4 \%)$, das exportações $(11,5 \%)$ e do consumo das famílias $(6,9 \%)$.

Segundo Baltar et al. (2010), a economia brasileira, após 2004, apresentou uma ampliação da atividade econômica que favoreceu e foi favorecida pela expressiva ampliação da ocupação, do emprego formal, dos rendimentos do trabalho, das transferências de renda e do aumento real do salário mínimo. A situação econômica brasileira, após 2004, sinalizava a possibilidade desse padrão de crescimento se dar 
de maneira sustentável. Ademais, as expansões do consumo e do investimento ganharam um grande impulso, em decorrência da articulação da elevação da renda familiar com a ampliação do crédito ao consumo.

Fica evidente que não somente o contexto internacional do início da década foi importante para esse processo. Para Baltar et al. (2010), a partir de 2007, houve uma alteração na postura do governo em relação à necessidade de se dar continuidade ou mesmo de se acelerar o crescimento econômico. Os sinais dessa alteração estão no lançamento do PAC (tentativa de ampliar o investimento público em infraestrutura ativação do investimento autônomo), na restauração do quadro de pessoal e do nível dos salários dos funcionários públicos; na manutenção do ritmo de aumento real do salário mínimo; na ampliação das despesas da seguridade; na capitalização do BNDES pelo Tesouro Nacional, que atuou na articulação da formação de grupos nacionais e no apoio ao investimento das empresas; e na ampliação dos programas de transferência de renda, extremamente importantes para a ampliação do consumo e da diminuição da pobreza.

A retomada do crescimento econômico após 25 anos de estagnação proporcionou um ambiente extremamente favorável à elevação do nível de emprego, à diminuição do desemprego e à recuperação da renda das famílias, num contexto de relativa estabilidade inflacionária. Essa estabilidade proporcionou uma ampliação real da renda que, somada ao aumento do crédito, permitiram a criação de um ciclo virtuoso entre renda - crédito - consumo.

Ademais, os investimentos de caráter autônomo, isto é, aqueles ativados pela ampliação dos gastos públicos em infraestrutura econômica e social, bem como os investimentos privados em novos projetos produtivos, mostraram-se como uma das principais fontes de dinamismo da atividade econômica, especialmente após 2006.

Nesse sentido, é razoável afirmar-se que as duas principais variáveis que propiciaram esse novo padrão de crescimento foram o consumo e, em especial, o investimento. Ambas permitiram a reativação da atividade econômica e possibilitaram uma alteração relevante na condição socioeconômica de grande parcela da população brasileira. 
É evidente que o processo recente de redução da desigualdade de renda com elevação da renda per capita das famílias esteve intimamente relacionado ao processo de expansão econômica. No entanto, não se pode desconsiderar a importância das políticas sociais de transferência de renda, bem como a de valorização real do salário mínimo, que garantiram a ampliação da renda de parcela expressiva da população que se encontrava na base da estrutura distributiva.

No entanto, segundo Dedecca (2013), os efeitos positivos desse ciclo virtuoso só não foram mais amplos devido à valorização cambial, que permitiu que parte dessa virtuosidade fosse deslocada para o mercado externo pela via das importações. O que se observou na sociedade brasileira foi um "movimento inédito na história do desenvolvimento brasileiro", que pode ser caracterizado pela associação positiva entre crescimento, renda, redução da desigualdade, baixa inflação e democracia (Dedecca, 2013, p. 134).

Como apresentado, essa conjuntura se mostrou extremamente favorável ao processo de redução da desigualdade nos anos 2000, abrindo espaço para que esse tema fosse discutido e ganhasse a importância devida, num país em que as diferenças econômicas e sociais possuem um caráter historicamente estrutural. Nesse sentido, faz-se necessária a apresentação de algumas constatações e interpretações sobre tal processo.

\section{Evidências, avanços e interpretações sobre a queda recente da desigualdade}

Diversos estudos na primeira metade da década de 2000 se debruçaram sobre o processo de redução da desigualdade de renda que se desenhava. O Relatório de 2006 produzido pelo IPEA aponta que o Brasil conquistou, entre 2001 e 2004, uma redução significativa e acentuada da desigualdade de renda familiar per capita. Por si só esse resultado já se mostra importante e, ainda mais, quando acompanhado de uma expressiva redução da pobreza e da extrema pobreza.

IPEA (2006) afirma que a queda da desigualdade se deu de maneira acentuada, apresentando impactos expressivos sobre a redução da pobreza. Segundo o relatório, isso decorre do aumento maior da renda média dos mais pobres 
relativamente à média na $\neg$ cional. Aponta que, nesse período, o crescimento da renda média dos $20 \%$ mais pobres foi cerca de 20 pontos percentuais acima do observado entre os $20 \%$ mais ricos. Ademais, afirma que a queda de $4 \%$ do índice de GINI representou uma redução de $3,2 \%$ na proporção de pessoas extremamente pobres, significando a retirada de mais de cinco milhões de brasileiros dessa condição.

No que se refere aos determinantes imediatos da queda da desigualdade da renda familiar per capita, IPEA (2006) avalia cinco dimensões: 1) características demográficas das famílias - houve uma homogeneização demográfica no interior dos grupos de renda; 2) transferências de renda - expansão do valor e da cobertura de transferências como pensões e aposentadorias públicas, Benefício de Prestação Continuada (BPC), e Bolsa Família; 3) remuneração de ativos - pouco ou nenhum peso para a queda da desigualdade; 4) acesso ao trabalho, desemprego e participação no mercado de trabalho apresentaram baixo peso para a melhora da desigualdade; e 5) distribuição dos rendimentos do trabalho - indicando que a diminuição da disparidade dos rendimentos do trabalho explica metade da queda na desigualdade de renda familiar do período, sendo influenciada positivamente pela diminuição das diferenças de gênero, de nível educacional e de localização espacial.

Esse mesmo relatório afirma que, apesar da queda recente da desigualdade de renda, essa permaneceu extremamente elevada. Ademais, a renda apropriada pelo $1 \%$ mais rico da população é igual à renda apropriada pelos $50 \%$ mais pobres, fazendo com que o Brasil continuasse ocupando uma posição de negativo destaque no plano internacional.

Salm (2006) faz uma crítica incisiva a esse estudo, partindo da constatação de que as visões apresentadas relegam a importância de fatores estruturais, como o papel do Estado Nacional, para a conformação do quadro de desigualdade no país. Segundo Salm (2006), o relatório do IPEA não leva em conta a capacidade de o crescimento econômico e de as alterações na estrutura produtiva resgatarem a mão de obra de atividades de baixa produtividade. Ademais, afirma que tal interpretação não aborda a importância de mudanças nos preços relativos que afetam, de forma diferente, ricos e pobres, nem os impactos distributivos da dinâmica da acumulação, principalmente aqueles oriundos da ampliação dos investimentos. 
Outra importante crítica que Salm (2006) faz ao relatório pode ser aplicada aos trabalhos de Barros et al (2007; 2010). Para o autor, esses estudos invertem o sentido da determinação entre diminuição da desigualdade e diminuição da pobreza. O autor elucida que, ao se considerar a queda da pobreza uma consequência de melhorias da distribuição de renda, desqualifica-se a importância do crescimento econômico para tal processo. Na realidade, para o autor, é a diminuição da pobreza que contribui para a redução dos níveis de desigualdade de renda. Ademais, afirma que inverter o sentido da determinação é trazer, implicitamente, a mensagem de que bastaria distribuir renda para diminuir a pobreza, não importando, portanto, se o País cresce ou não, se cria ou não empregos de melhor qualidade, se aumenta a produtividade ou se ocorrem transformações estruturais que favoreçam os mais os pobres.

É necessário notar que, no processo de redução da desigualdade de renda, a queda do Índice de Gini deu-se por desempenhos diferenciados dos níveis de rendimento real dos distintos estratos de renda. As implicações de cada um desses processos são completamente diferentes para o padrão de vida de cada estrato. Segundo Soares (2006), até 2004, a redistribuição de renda que ocorreu na sociedade brasileira deu-se a partir do ganho dos 70\% mais pobres em contrapartida a uma perda dos 30\% mais ricos. Isso representa uma melhora da distribuição de renda sem aumento de bem-estar, pois a diminuição das diferenças de renda ocorreu com queda da renda média. ${ }^{10}$

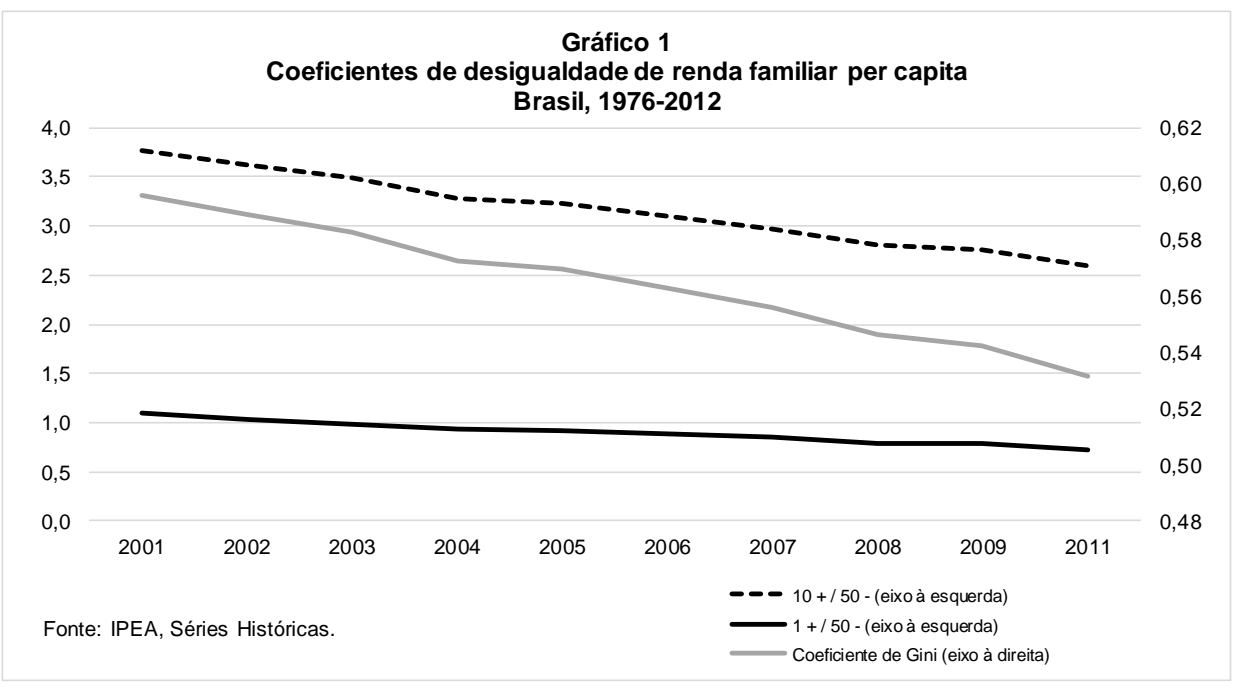

10 Ver Soares (2006). 
Para Dedecca (2010), a desigualdade de renda no Brasil no início da década, até 2003 mais precisamente, decorreu da queda na renda dos estratos superiores da distribuição e da proteção aos estratos inferiores pela valorização do salário mínimo. Para o autor, o quadro desse período deve ser considerado problemático, pois a redução do Índice de Gini expressou uma tendência de desvalorização de boa parte dos níveis de remuneração e reiterou a condição estrutural de baixos salários, que caracterizou historicamente o mercado de trabalho brasileiro. ${ }^{11}$

Já o período de 2003 a 2008 apresentou outra característica. O cenário relativamente mais favorável à base de estrutura de renda, indicado pela redução do coeficiente de Gini e pelas relações do $1 \%$ e dos $10 \%$ mais ricos com os $50 \%$ mais pobres, ocorreu pari passu à recuperação de todos os níveis de rendimentos do trabalho, um movimento inédito na história brasileira. Para Dedecca (2010), houve pela primeira vez uma redução da desigualdade de renda sem desvalorização do mercado de trabalho e com elevação da renda média e do bem-estar. Desse modo, a queda da desigualdade de renda ocorreu devido a um aumento relativamente maior das remunerações dos estratos inferiores, em comparação ao topo da estrutura de renda.

O Gráfico 1 indica que a década de 2000 foi marcada por uma tendência de melhoria da distribuição pessoal da renda. A diferença, em termos de renda familiar per capita, entre os $10 \%$ mais ricos e os $50 \%$ mais pobres, reduziu-se de mais de três vezes e meia para menos de duas vezes e meia, melhorando a distribuição de renda em favor das camadas da base da pirâmide. O Índice de Gini, por sua vez, apresentou uma queda de $10 \%$ em pouco mais de uma década, corroborando o ambiente favorável traçado anteriormente.

A partir do Gráfico 2, pode-se observar, também, um cenário favorável do ponto de vista da distribuição funcional da renda. Com exceção de 2002, em todos os anos do período de 2001 a 2010, o crescimento real da massa de rendimentos do emprego formal foi superior ao crescimento do PIB, indicando um aumento da participação dos salários na renda nacional. ${ }^{12}$ Esse movimento foi confirmado pelas informações das Contas Nacionais que, apesar da queda entre 2001 e 2004, apresentaram um aumento da participação dos salários e dos ordenados no PIB, que passou de 30,9\% para 33,2\% entre 2004 e 2010. A queda no ritmo de crescimento do produto em 2009

\footnotetext{
${ }^{11}$ Essa visão corrobora o quadro apresentado sobre as heranças históricas. Ver também Baltar e Proni (1996), Soares (2006) e Dedecca (2010).

12 Ver, também, Bastos (2012).
} 
refletiu-se nos resultados das Contas Nacionais, que apresentaram uma redução da participação da renda do trabalho, contrariando as informações da RAIS, que mostraram um crescimento da massa salarial naquele ano. Não se pode deixar de afirmar que essa melhor distribuição funcional da renda se deu em um contexto de inflação relativamente estável e de queda da taxa de desemprego (Gráfico 2).

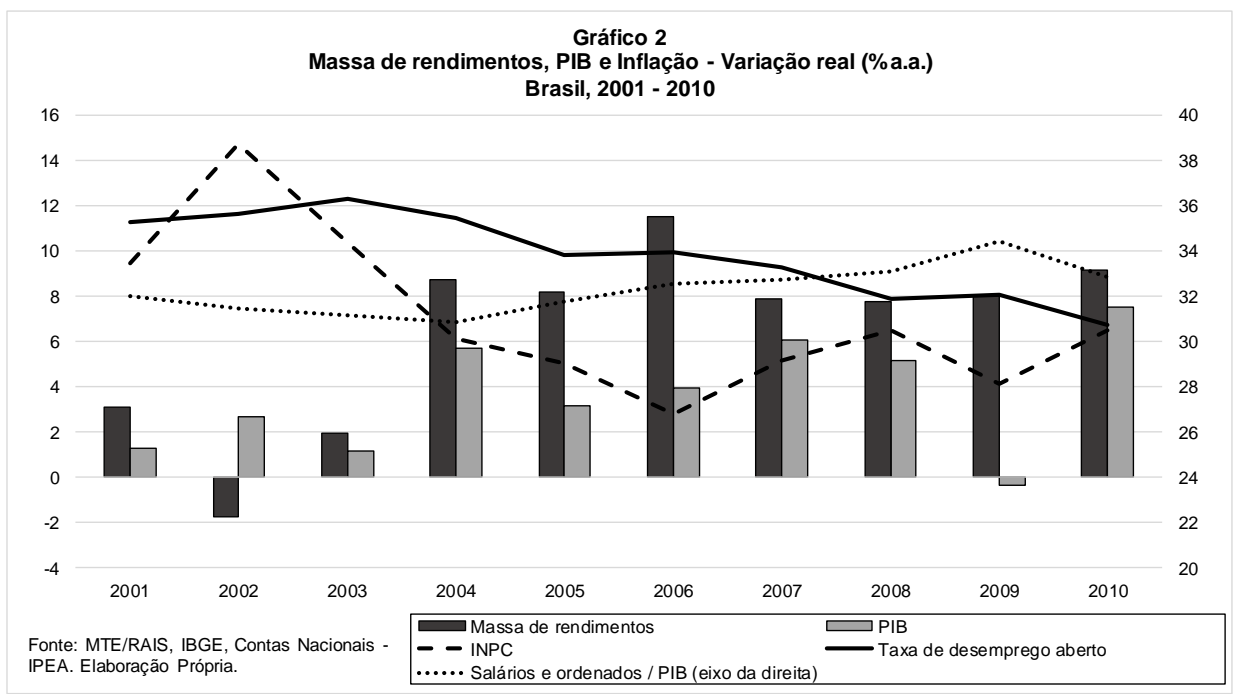

Quanto à dimensão econômica da desigualdade, destaca-se que o crescimento do PIB permitiu a criação de condições favoráveis do ponto de vista do mercado de trabalho, a partir do crescimento do emprego, da ampliação da formalização, da recuperação real dos salários e da valorização do salário mínimo, principalmente após 2004, o que proporcionou uma melhora das distribuições pessoal e funcional da renda corrente.

A especificidade da década de 2000 , no que diz respeito ao processo de redução da desigualdade de renda, não se restringe ao fato de esse ter ocorrido em um ambiente de recomposição do rendimento médio da população, nem à melhor distribuição dos rendimentos do trabalho. Nesse período, ocorreu também a redução da pobreza monetária, beneficiada pela geração expressiva de empregos, pela elevação sistemática dos salários da base da pirâmide social e pelas políticas sociais (previdência e transferência direta de renda). ${ }^{13}$

\footnotetext{
${ }^{13}$ Ver Dedecca (2013).
} 
Barros et al. (2010) apresentam outro ponto de vista. Para os autores, a redução da desigualdade de renda no Brasil ocorreu, em grande medida, por mudanças na renda do trabalho associadas às melhorias no capital humano da força de trabalho, devido a uma alteração positiva dos níveis educacionais. Apontam, também, que uma parcela não desprezível da queda da desigualdade de renda esteve associada à redução dos graus de discriminação (cor e gênero) e de segmentação no mercado de trabalho (setores de atividades e regiões). Quanto a esse aspecto, destaca-se que os autores diminuem o peso do cenário econômico e das decisões por parte do Estado de incentivo ao crescimento e de valorização real do salário mínimo. Com base na teoria do capital humano, apontam que a educação é a fonte principal para a redução da desigualdade.

Isto é, a competição entre os trabalhadores no interior do mercado de trabalho garantiria àqueles mais aptos ou mais qualificados (com maiores méritos) a oportunidade de receber maiores salários. Essa ideia, além de desconsiderar que a desigualdade é um fenômeno muito mais complexo, ainda nega que, como demonstrou Keynes (1936), o nível de emprego depende das decisões dos agentes no âmbito da produção, fora do mercado de trabalho. Isso implica em se assumir que a educação não é capaz, per se, de garantir melhores empregos/salários se a dinâmica econômica não for tal que possibilite a ampliação do nível de emprego.

Deve-se destacar que, no final de 2008, o Brasil entrou em um período de incerteza sobre a continuidade do processo de redução da desigualdade de renda devido à crise internacional que impactou sobremaneira não só o Brasil, mas toda a economia mundial. Essa incerteza esteve associada à possibilidade de sustentação do ritmo de crescimento econômico observado até 2008 e a capacidade de manutenção das políticas sociais de transferência de renda e da política de valorização do salário mínimo, que poderiam ser impactadas pelo baixo dinamismo da atividade econômica.

Hoffmann (2013) considera que a redução da desigualdade de renda corrente entre 2003 e 2010 deveu-se ao fortalecimento e à ampliação dos mecanismos progressivos de distribuição de renda como o Programa Bolsa Família e o Benefício de Prestação Continuada (BPC), o que corrobora a preocupação quanto à 
manutenção desses mecanismos em um contexto de diminuição do ritmo de crescimento e crise. Segundo Hoffmann (2014), distintos índices de concentração de renda, com exceção do Índice de Theil (mais sensível a mudanças na cauda direita da distribuição) que mostrou um leve aumento entre 2011 e 2012, indicavam nos primeiros anos da década de 2010 a continuidade do movimento de redução da desigualdade de renda.

Com base nessas considerações, pode-se afirmar que o Brasil vivenciou um momento inédito em sua história. Tanto em termos de distribuição pessoal quanto funcional da renda corrente, os indicadores apontaram para uma tendência de redução da desigualdade em sua dimensão econômica. ${ }^{14}$ Os fatores que contribuíram para isso foram a melhora no acesso ao mercado de trabalho, em especial em seu segmento formal, a elevação do nível de emprego com redução do desemprego e a expansão da renda. Essa por sua vez, garantiu uma maior capacidade de consumo das famílias, que, associada à ampliação do crédito, permitiram o acesso de milhões de pessoas a determinados bens de consumo de uso individual. Uma grande quantidade de pessoas deixou a condição de miséria e de pobreza monetárias. Ademais, a melhoria dos níveis de renda dos estratos intermediários da distribuição permitiu que muitas pessoas ascendessem socialmente às classes médias da distribuição da renda. ${ }^{15}$

De modo geral, a redução da desigualdade de renda dos anos 2000 esteve associada à continuidade dos programas de transferência de renda, à manutenção da política de valorização do salário mínimo ${ }^{16}$ e à contínua redução do desemprego, em um ambiente de crescimento econômico.

A melhoria das distribuições pessoal e funcional da renda, no contexto de crescimento econômico dos anos 2000, beneficiou-se da relativa estabilidade inflacionária e do chamado bônus demográfico. As menores taxas de fecundidade ocorreram conjuntamente com a ampliação da parcela da população em idade

\footnotetext{
${ }^{14}$ Estudos recentes baseados nas informações das declarações de imposto de renda têm apontado para uma estabilidade na participação dos mais ricos (1\% mais rico) na renda total, o que indicaria uma manutenção da desigualdade não captada pelas pesquisas domiciliares. Para mais detalhes ver Castro (2014), Souza (2016) e Morgan (2017).

${ }^{15}$ Ver Dedecca et al. (2014).

${ }^{16}$ A valorização do salário mínimo é referência para o piso da previdência social, o que significa que a valorização desse piso também contribui para a diminuição da desigualdade. Segundo Hoffmann (2014), os rendimentos de aposentadorias e pensões pagas pelo sistema de previdência do INSS ou do regime especial de funcionários públicos que se encontravam próximas ao valor do salário mínimo mostraram-se importantes para a redução da desigualdade de renda no Brasil do período de 2001 a 2012.
} 
economicamente ativa e a redução da razão de dependência. ${ }^{17}$ Dadas as características do processo, a manutenção da queda da desigualdade de renda dependeria da capacidade de se sustentar uma dinâmica econômica que permitisse ao mercado de trabalho absorver o aumento da população, ainda que essa esteja crescendo em ritmo menos acelerado. ${ }^{18}$

Resta saber se a redução da desigualdade de renda, ao basear-se em um padrão de crescimento orientado pela ampliação da renda e do consumo, foi acompanhada de uma redução para além de sua dimensão econômica. Em outras palavras, deve-se explorar se os resultados observados para essa dimensão foram acompanhados de reduções das desigualdades em outras dimensões, como aquelas associadas à insuficiência/privação no acesso a bens e serviços públicos de uso coletivo, intimamente relacionados à dinâmica dos investimentos em infraestrutura social.

\section{Limites do processo recente de redução da desigualdade no Brasil}

A grande maioria das abordagens sobre desigualdade utiliza basicamente duas fontes de dados para mensurar concentração de renda: pesquisas domiciliares e as Contas Nacionais. Deve ficar claro que os resultados propiciados pela Pesquisa Nacional por Amostra de Domicílios (PNAD) indicam que a queda da desigualdade está circunscrita a alterações na distribuição individual da renda do trabalho, da previdência social e da transferência direta de renda. No que se refere à distribuição funcional, captada pelas Contas Nacionais, é importante evidenciar que, somente após 2004, é que se verificou uma melhora na distribuição devido à ampliação da participação da renda do trabalho (Gráfico 2).

Como mostram Salm (2006) e Dedecca (2008, 2010), até 2004, a melhora da distribuição pessoal da renda processou-se concomitantemente a uma deterioração da distribuição funcional, com uma clara penalização da renda do trabalho. Portanto, cabe destacar a importância de se ter claro qual o perfil dessa mudança e a qual dimensão ela está associada.

O que se observou após 2004 é que houve uma melhora da distribuição, tanto pessoal quanto funcional, possibilitada pelo contexto de crescimento econômico, com

\footnotetext{
${ }^{17}$ Segundo IPEA (2010), a redução da dependência diminui o peso econômico da inatividade e a população em idade ativa, ao produzir, cria recursos adicionais que podem ser revertidos em poupança e/ou investimentos, importantes para o desenvolvimento do país.

18 Esse é o desafio brasileiro do período pós crise de 2015.
} 
elevação dos postos de trabalho, especialmente de seu segmento formal, ampliação de políticas públicas de transferência direta de renda e de valorização do salário mínimo, que se somaram à relativa estabilidade inflacionária (Salm, 2006; Dedecca, 2010)..$^{19}$

Dada a especificidade desse processo, a redução da desigualdade encontravase condicionada a um bom funcionamento do mercado de trabalho, à capacidade de absorção pela dinâmica econômica do crescimento da população e, também, à capacidade de o Estado brasileiro ampliar o valor real dos benefícios oriundos das políticas públicas.

No entanto, o entendimento da complexidade desse fenômeno representa assumir que o avanço do capitalismo e as transformações nas condições de produção, distribuição e vida das pessoas impuseram diversos riscos econômicos e sociais. Nesse sentido, o papel das instituições públicas para distribuição dos resultados econômicos e sociais do desenvolvimento capitalista tornou-se um elemento fundamental para o entendimento da desigualdade enquanto um processo na conformação da sociedade moderna.

Ao menos duas dimensões devem ser reconhecidas para se abordar de forma mais aprofundada esse tema: uma de natureza econômica e outra social. A primeira está associada à distribuição dos fluxos e estoques de renda e a segunda refere-se ao acesso aos bens e serviços sociais.

Grande parte dos estudos sobre desigualdade restringem-se a essa primeira dimensão. Isso significa que se limitam aos fluxos, isto é, à renda corrente auferida pela população nas formas de rendimento do trabalho e da proteção social, sem levar em conta o sistema de tributação que incide sobre a renda e, muito menos, os ganhos derivados dos estoques - ativos financeiros, não-financeiros e patrimônios. ${ }^{20}$

A segunda dimensão possui natureza estrutural e coletiva. Portanto, sua abordagem necessita da identificação das parcelas específicas da sociedade que podem se encontrar em situação de desvantagem quanto ao acesso aos bens e serviços públicos.

\footnotetext{
19 Segundo Hoffmann (2010) "as aposentadorias e pensões do Regime Geral de Previdência Social (pagas pelo INSS)" apresentam-se como uma fonte progressiva para a redução da desigualdade de renda no Brasil do período recente.

${ }^{20}$ De acordo com Dedecca (2013, p. 137), apenas recentemente tem sido objeto de maior preocupação, entre economistas e sociólogos, os problemas oriundos da desigualdade patrimonial. Para ele isso se deu em grande medida à "crescente financeirização da riqueza produzida desde os anos 80 e que se encontra na raiz da crise atual". Ademais, afirma que "o tratamento dessa dimensão da desigualdade econômica encontra enormes dificuldades, em razão da pouca disponibilidade de dados para a análise".
} 
Dentre os bens e serviços que definem a dimensão social da desigualdade pelo acesso, destacam-se: água/saneamento, energia, transporte, habitação, educação, saúde, alimentação, terra, meio ambiente, lazer, dentre outros.

Não se pode deixar de reconhecer certo avanço feito pelos estudos sobre a queda da desigualdade de renda corrente ao mapear a contribuição de elementos como: o salário mínimo, a transferência de renda e o aumento do emprego para a evolução de indicadores de concentração. No entanto, isso se mostra insuficiente para caracterizar e quantificar a complexidade da evolução histórica e estrutural do quadro das desigualdades socioeconômicas no Brasil.

Para superar as restrições desse tipo de abordagem, Dedecca (2013), Trovão (2015) e Araújo (2017) propõem análises multidimensionais da desigualdade com base em indicadores que contemplem, em parte, as distintas dimensões, sejam elas de ordem econômica ou social. ${ }^{21}$

Em consonância com essas abordagens, o presente estudo elabora um conjunto de indicadores baseados nas informações dos Censos Demográficos de 2000 e 2010, o que permite uma avaliação dos resultados do período em que se observou um contexto favorável da economia, que permitiu uma alteração da condição de desigualdade no Brasil.

A Tabela 1 traz elementos importantes que permitem elucidar comparativamente as condições socioeconômicas da população em extrema pobreza, da população pobre e dos $10 \%$ mais ricos da estrutura de renda familiar per capita, a partir de cinco dimensões: mercado de trabalho e renda, condições de vida e consumo, educação, demografia, saúde e discriminação social. ${ }^{22}$

De modo geral, os dados dos Censos Demográficos indicam uma melhora da posição relativa dos mais pobres, nas diversas dimensões, comparativamente à população que se encontra no topo da distribuição de renda.

Quanto à dimensão mercado de trabalho e renda, o que chama atenção é o aumento da taxa de formalização entre os mais pobres, acompanhado por uma queda no desemprego. Nessa dimensão, a elevação da incidência dos programas sociais para as famílias mais pobres na década de 2000 é um elemento que corrobora a

\footnotetext{
${ }_{21}$ Para maiores informações sobre a construção dos indicadores utilizados, ver anexo.

22 O conceito de extrema pobreza utilizado no presente estudo está baseado na referência adotada pelo Programa Brasil sem Miséria do Governo Federal. O PBSM considera extremamente pobre aquele que auferir rendimento familiar inferior a $\mathrm{R} \$ 70,00$ per capita. Vale destacar que a referência para se produzir os indicadores do ano 2000 foi o valor de $\mathrm{R} \$ 70,00$ deflacionado pelo INPC. O conceito de pobreza está baseado em uma determinação constitucional, que reconhece que pobre é aquele que aufere rendimento familiar per capita inferior a meio salário mínimo.
} 
importância do papel do Estado para a melhora da condição de desigualdade no

Brasil.

Tabela 1

Indicadores multidimensionais de desigualdade

Brasil, 2000 - 2010

\begin{tabular}{|c|c|c|c|c|c|c|}
\hline \multirow[b]{2}{*}{ MERCADO DE TRABALHO E RENDA } & \multicolumn{2}{|c|}{ Extrema Pobreza } & \multicolumn{2}{|c|}{ Pobreza } & \multicolumn{2}{|c|}{$10 \%$ mais ricos } \\
\hline & 2000 & 2010 & 2000 & 2010 & 2000 & 2010 \\
\hline Taxa de desemprego & 22,5 & 24,8 & 22,2 & 15,9 & 5,0 & 2,0 \\
\hline Taxa de formalização & 9,8 & 4,6 & 21,2 & 33,0 & 64,7 & 80,3 \\
\hline Taxa de assalariamento & 60,3 & 48,0 & 68,6 & 73,1 & 62,1 & 67,2 \\
\hline Incidência do trabalho agrícola & 40,3 & 19,3 & 30,8 & 19,9 & 2,7 & 2,9 \\
\hline Incidência da previdência social & 13,1 & 3,3 & 21,3 & 17,5 & 41,0 & 37,8 \\
\hline Incidência de programas sociais & 3,2 & 81,4 & 2,8 & 51,0 & 1,3 & 0,5 \\
\hline Incidência da renda do trabalho & 74,8 & 37,0 & 79,2 & 74,5 & 86,3 & 85,5 \\
\hline Participação da renda do trabalho na renda total & 76,2 & 37,1 & 77,0 & 72,1 & 77,9 & 71,3 \\
\hline \multicolumn{7}{|l|}{ CONDIÇÕES DE VIDA / CONSUMO } \\
\hline Densidade de morador por dormitório & 2,7 & 2,3 & 2,5 & 2,1 & 1,4 & 1,2 \\
\hline Densidade de morador por banheiro & 13,3 & 6,8 & 8,1 & 4,9 & 1,3 & 1,1 \\
\hline Proporção de famílias sem parede apropriada & - & 14,8 & - & 7,3 & - & 0,3 \\
\hline Proporção de famílias sem banheiro exclusivo do domicílio & 58,4 & 35,6 & 41,1 & 17,4 & 0,9 & 0,2 \\
\hline Proporção de famílias sem rede apropriada de esgoto & 42,9 & 55,4 & 44,5 & 48,9 & 7,9 & 8,2 \\
\hline Proporção de famílias sem água encanada & 23,3 & 29,7 & 15,5 & 14,7 & 0,6 & 0,4 \\
\hline Proporção de famílias sem coleta lixo apropriada & 59,8 & 49,7 & 45,3 & 28,2 & 2,8 & 1,5 \\
\hline Proporção de famílias sem acesso à energia elétrica & 23,5 & 7,1 & 14,4 & 3,1 & 0,2 & 0,0 \\
\hline Proporção de famílias sem televisão & 38,8 & 16,1 & 26,7 & 8,5 & 1,1 & 0,8 \\
\hline Proporção de famílias sem máquina de lavar & 95,1 & 91,7 & 91,5 & 80,6 & 22,3 & 14,3 \\
\hline Proporção de famílias sem geladeira & 57,4 & 29,5 & 39,8 & 14,5 & 1,0 & 0,6 \\
\hline Proporção de famílias sem telefone (fixo ou celular) & 94,9 & 44,0 & 90,5 & 24,5 & 11,9 & 0,7 \\
\hline Proporção de famílias sem computador & 98,5 & 95,6 & 98,5 & 87,4 & 51,3 & 18,2 \\
\hline Proporção de famílias sem internet no domicílio & - & 1,8 & - & 5,0 & - & 4,9 \\
\hline Proporção de famílias sem veículo particular & 94,1 & 77,3 & 90,8 & 71,1 & 19,1 & 14,5 \\
\hline \multicolumn{7}{|l|}{ EDUCAÇÃO } \\
\hline Taxa analfabetismo & 45,7 & 22,5 & 38,4 & 15,8 & 6,2 & 1,0 \\
\hline Taxa escolarização crianças 6 a 14 anos & 87,7 & 95,8 & 89,8 & 96,3 & 98,9 & 98,4 \\
\hline Defasagem escolar (6 a 14 anos) & 60,0 & 52,9 & 56,5 & 49,1 & 31,5 & 35,6 \\
\hline Incidência do ensino médio completo & 2,5 & 8,5 & 4,8 & 15,4 & 38,9 & 31,4 \\
\hline Incidência do Ensino Superior & 2,4 & 0,4 & 2,0 & 0,9 & 36,7 & 52,7 \\
\hline \multicolumn{7}{|l|}{ DEMOGRAFIA } \\
\hline Razão dependência & 99,5 & 80,1 & 83,1 & 69,0 & 31,3 & 28,5 \\
\hline Tamanho médio das famílias & 5,7 & 4,6 & 5,0 & 4,4 & 2,9 & 2,5 \\
\hline Proporção de famílias com chefia feminina & 19,3 & 41,4 & 21,9 & 40,1 & 25,8 & 35,8 \\
\hline Proporção de famílias com residência inferior a 4 anos & 3,4 & 2,4 & 3,8 & 3,1 & 5,4 & 6,5 \\
\hline Proporção de famílias com chefia de não brancos & 69,9 & 74,7 & 63,9 & 68,1 & 15,8 & 22,1 \\
\hline \multicolumn{7}{|l|}{ SAÚDE - AGRAVANTE DA CONDIÇÃO SOCIAL } \\
\hline $\begin{array}{l}\text { Proporção de famílias com pelo menos uma pessoa com } \\
\text { dificuldade permanente de enxergar }\end{array}$ & 34,1 & 44,5 & 33,2 & 44,6 & 14,4 & 27,1 \\
\hline $\begin{array}{l}\text { Proporção de famílias com pelo menos uma pessoa com } \\
\text { dificuldade permanente de ouvir }\end{array}$ & 12,0 & 13,6 & 12,3 & 14,7 & 7,4 & 9,7 \\
\hline $\begin{array}{l}\text { Proporção de famílias com pelo menos uma pessoa com } \\
\text { dificuldade permanente de caminhar ou subir degraus }\end{array}$ & 15,1 & 15,9 & 16,1 & 18,1 & 8,5 & 11,1 \\
\hline $\begin{array}{l}\text { Proporção de famílias com pelo menos uma pessoa com } \\
\text { deficiência mental/intelectual permanente }\end{array}$ & - & 4,7 & - & 5,4 & - & 1,6 \\
\hline \multicolumn{7}{|l|}{ DISCRIMINAÇÃO } \\
\hline Diferença dos rendimentos entre mulheres e homens & 64,6 & 66,7 & 67,2 & 65,0 & 50,7 & 61,3 \\
\hline Diferença dos rendimentos entre negros e brancos & 97,8 & 102,5 & 89,7 & 87,6 & 76,2 & 80,6 \\
\hline Proporção de crianças negras em defasagem escolar & 70,7 & 56,0 & 66,4 & 52,1 & 38,1 & 38,2 \\
\hline Proporção de crianças brancas em defasagem escolar & 63,1 & 52,9 & 56,5 & 48,3 & 30,8 & 35,7 \\
\hline Taxa de analfabetismo de negros & 47,0 & 23,6 & 40,0 & 17,4 & 6,4 & 1,6 \\
\hline Taxa de analfabetismo de brancos & 42,3 & 18,9 & 35,3 & 12,4 & 6,2 & 0,8 \\
\hline
\end{tabular}

Fonte: IBGE - Censo Demográfico. Elaboração própria 
Os indicadores que demonstram a evolução das condições de vida indicam uma melhora do acesso à energia elétrica e à coleta de lixo. No entanto, ao se observar o acesso a outros bens públicos, como saneamento básico e água encanada, percebe-se uma elevada desigualdade associada a essa dimensão, o que indica a necessidade de um esforço expressivo do ponto de vista da infraestrutura social capaz de alterar estruturalmente essa condição desigual.

No que se refere ao consumo, houve uma ampliação do acesso a diversos bens como televisão, geladeira, máquina de lavar, e, principalmente, telefone. O aumento da renda, a melhora do mercado de trabalho e o acesso ao crédito nesse período favoreceu a expansão do consumo de bens duráveis.

A ampliação do acesso a bens ofertados pelo mercado indica uma redução da desigualdade em sua dimensão econômica. No entanto, esse movimento ocorreu sem que houvesse alterações estruturais quanto ao acesso a bens públicos essenciais como saneamento e água.

$\mathrm{Na}$ dimensão educacional houve uma melhoria das condições da população mais pobre. O crescimento da taxa de escolarização foi acompanhado por uma redução da defasagem escolar e da taxa de analfabetismo da população adulta. No entanto, o caminho para que se alterem as diferenças entre os mais ricos e os mais pobres ainda é longo. Esse cenário fica ainda mais claro quando se observam indicadores que retratam a ínfima incidência do ensino superior e do ensino médio entre as populações pobre e extremamente pobre. As informações referentes à dimensão demográfica apontam uma situação generalizada de diminuição do tamanho médio das famílias, o que permite uma suavização da condição de pobreza. Ademais, cabe destacar que houve uma ampliação generalizada entre pobres e ricos da proporção de famílias com chefia de não brancos (pretos, pardos e índios) e de mulheres, não configurando assim, uma alteração expressiva nas diferenças entre pobres e ricos, isto é, da desigualdade.

A dimensão da saúde foi abordada levando-se em conta as limitações dos dados dos Censos Demográficos. Esses não possibilitam auferir o acesso, muito menos a qualidade dos serviços de saúde, públicos ou privados. No entanto, permitem avaliar algumas informações que podem ser entendidas como fontes de agravamento 
da condição de diferenciação social. Nesse sentido os dados disponíveis indicam a elevação da proporção de famílias com pelos menos um membro com alguma dificuldade, seja ela locomotora, visual ou auditiva. Isso representa um agravamento da condição das famílias mais pobres, que além dos problemas associados à sua condição desfavorável, ainda terão que lidar com outras dificuldades associadas aos cuidados especiais que esses tipos de deficiências exigem.

Por fim, quanto à dimensão da discriminação social, percebe-se uma redução da desigualdade entre negros e brancos, tanto para a renda quanto para o nível educacional. Houve também uma melhora da desigualdade dos rendimentos entre mulheres e homens. No entanto, há que se reconhecer que a desigualdade entre negros e brancos e entre mulheres e homens ainda é sensivelmente elevada.

\section{Considerações Finais: Desafios para avançar em direção a uma redução estrutural das desigualdades}

A primeira década do século XXI representou um marco para a economia brasileira. Nesse período recuperou-se a atividade econômica, ampliou-se o nível de emprego e renda e reduziu-se a desigualdade de renda corrente.

Esse cenário proporcionou uma redução importante nos níveis da desigualdade de renda corrente e evidenciou a importância do crescimento da atividade econômica e da recuperação do mercado de trabalho. Tanto o crescimento econômico como a promoção de políticas públicas diretamente relacionadas ao mercado de trabalho e à renda, bem como àquelas orientadas para a expansão do crédito ao consumidor a às empresas, mostraram-se fundamentais para a evolução favorável no sentido da queda da desigualdade.

É evidente que instrumentos distributivos de natureza monetária foram e continuarão sendo importantes. No entanto, como desigualdade é um fenômeno que extrapola a dimensão econômica e contempla necessidades de ordem multidimensional como: água/saneamento, energia, transporte, habitação, saúde, educação, alimentação, acesso à terra, previdência, trabalho e meio ambiente, uma menor desigualdade só poderá ser alcançada se os desafios nessas outras dimensões forem enfrentados. 
Os dados apresentados apontaram um movimento muito mais expressivo de redução da desigualdade nas dimensões econômicas relativamente àquelas de natureza social. Demonstraram também que ainda persistem, apesar da relativa melhora, grandes disparidades entre os mais ricos e os mais pobres.

Nesse sentido, o desafio do Brasil não passa por tentar replicar o que se processou nos anos 2000. O grande desafio é identificar aquilo que, de certo modo, contribuiu para alterar o quadro de desigualdades econômicas e avançar no sentido de enfrentar os desafios colocados pelas dimensões de natureza social, sobretudo em um ambiente de crise econômica que tende a ampliar as desigualdades em todas essas dimensões.

Esse avanço não pode ser obtido sem a conscientização da existência de uma centralidade do fenômeno da desigualdade a ser incorporada pela agenda da política pública no âmbito de um projeto de desenvolvimento nacional.

O olhar para a desigualdade sob a perspectiva multidimensional é um primeiro passo no sentido de direcionamento do esforço da sociedade e do próprio Estado para superar os entraves que impedem que a desigualdade seja reduzida em suas dimensões sociais.

Evidentemente, esses entraves estão associados, não só à expansão da infraestrutura social, mas, também, à garantia de acesso por parte da população aos bens e serviços a ela associados.

O crescimento econômico e a recuperação do mercado de trabalho apresentaram-se como condições fundamentais para a redução da desigualdade de renda. O que implica em se afirmar que sua retomada e sustentação são passos importantes avançar nesse processo.

Portanto, se o caminho a ser escolhido é o de enfrentamento da desigualdade em suas múltiplas dimensões, um projeto de sociedade mais justa e menos desigual não pode deixar de considerar a possibilidade de criar uma sinergia entre crescimento econômico e redução das desigualdades.

O que se pretende deixar claro é que, reduzir desigualdades, especialmente as de natureza social, não precisa ser entendido apenas como um fim. Reduzir desigualdades é um meio para se alcançar uma dinâmica econômica sustentada e, 
ao menos tempo inclusiva. Em outras palavras, investir em infraestrutura social produz efeitos combinados, economias de escala e de recursos, além de complexas interações que possibilitam a uma nação buscar uma elevação de seu nível de desenvolvimento socioeconômico.

O Brasil pós 2015 conheceu uma reversão do processo vivido na primeira década do século XXI e sua causa está diretamente associada à diminuição expressiva dos investimentos e à redução do papel do Estado na condução e orientação dos rumos econômicos e sociais.

Reverter essa situação de crise pela retomada dos níveis de investimento (público e privado) pode parecer ser o caminho mais óbvio, especialmente por sua relação direta com o nível de emprego e renda. No entanto, a mensagem que se pretende deixar é que o desafio não é apenas voltar a investir e, consequentemente, crescer. É, na realidade, definir qual padrão de investimento e crescimento que se precisa obter para se alcançar uma sociedade mais justa e menos desigual. Certamente, qualificar o crescimento e, principalmente, os investimentos no sentido da expansão do acesso a bens e serviços sociais é um caminho complexo, porém, o mais acertado.

\section{REFERÊNCIAS}

ARAÚJO, J. B. Mercado de trabalho e desigualdade: o Nordeste brasileiro nos anos 2000. Tese de Doutorado em Desenvolvimento Econômico. Unicamp, Campinas, 2017.

BALTAR, P. et. al. Moving towards decent work. Labour in the Lula Government: reflections on recent brazilian experience. In: Global Labour University Working Papers. Paper no 9, 2010.

BALTAR, P.; PRONI, M. Sobre o regime de trabalho no Brasil: Rotatividade da mão-de-obra, emprego formal e estrutura salarial. In: BARBOSA DE OLIVEIRA, C.A. e MATTOSO, J. (orgs.) Crise e Trabalho no Brasil. Modernidade ou Volta ao Passado. São Paulo: Scritta, 1996, 344p.

BARBOSA, A. F. A formação do mercado de trabalho no Brasil: da escravidão ao assalariamento. Tese de Doutorado. Instituto de Economia da Unicamp, Campinas, 2003. 
BARROS, R. P. de; CARVALHO, M. de; FRANCO, S.; MENDONÇA, R. A importância da queda recente da desigualdade na redução da pobreza. TD 1256. Ipea, Rio de janeiro, 2007.

BARROS, R. P. de; CARVALHO, M. de; FRANCO, S.; MENDONÇA, R. Determinantes da queda na desigualdade de renda no Brasil. TD 1460. Ipea, Rio de janeiro, 2010.

CACCIAMALI, M. C. Padrão de acumulação e processo de informalidade: Brasil e México. Pesquisa \& Debate. PUCSP, São Paulo, v. 12, n.1, p. 5-43, 2001.

CANO, W. Desequilíbrios Regionais e Concentração Industrial no Brasil: 1930-1970. Global Editora. São Paulo, 1985.

CASTRO, F. A. Imposto de Renda da Pessoa Física: comparações internacionais, medidas de progressividade e redistribuição. Dissertação de Mestrado. Universidade de Brasília, 2014.

DEDECCA, C. S. Notas sobre a Evolução do Mercado de Trabalho no Brasil. Revista de Economia Política, vol. 25, noำ (97), pp. 94-111, janeiro-março de 2005.

Mimeo, 2010.

As desigualdades na sociedade brasileira. Campinas: IE/UNICAMP _

. Notas sobre crescimento, desenvolvimento e desigualdades no Brasil. In: Aporias para o planejamento público / organizadores: Geraldo Biasoto Junior, Luiz Antonio Palma e Silva. - São Paulo: FUNDAP, 2013. 289p.

DEDECCA, C. S.; TROVÃO, C. J. B. M.; SOUZA, L. F. Desenvolvimento e equidade: desafios do crescimento brasileiro. Novos Estudos CEBRAP (Impresso), v. 98, p. 23-41, 2014.

FURTADO, C. Formação Econômica do Brasil. Companhia Editora Nacional, São Paulo, 1959 [1974].

HOFFMANN, R. Tendências da distribuição de renda no Brasil e suas relações com o desenvolvimento econômico. In: TOLIPAN, R. e TINELLI, A. C. (orgs.) A controvérsia sobre a distribuição de renda no Brasil. Zahar, Rio de Janeiro, 1978.

Desigualdade da renda e das despesas per capita no Brasil, em 2002-

2003 e 2008-2009, e avaliação do grau de progressividade ou regressividade de parcelas da renda familiar. Economia e Sociedade, Campinas, v. 19, n. 3 (40), p. 647-661, dez de 2010.

Transferências de renda e desigualdade no Brasil (1995-2011). In:

Campello, T.; Neri, M. C. (Orgs) Programa Bolsa Família: uma década de inclusão e cidadania. Brasília: Ipea, 2013.

Fatos relevantes sobre a distribuição da renda no Brasil. 52ํㅡㄹ Congresso da SOBER, Painel 2. Goiânia, 27 a 30 de julho de 2014. Disponível em:

$<$ http://iepecdg.com.br/uploads/artigos/RDABRA6.pdf>. 
IPEA. Sobre a recente queda da desigualdade de renda no Brasil. Nota Técnica. Brasília: IPEA, 2006.

IPEA Estrutura etária, bônus demográfico e população economicamente ativa no Brasil: cenários de longo prazo e suas implicações para o mercado de trabalho. In: Macroeconomia para o desenvolvimento: crescimento, estabilidade e emprego. Capítulo 12. Instituto de Pesquisa Econômica Aplicada. Brasília: Ipea, 2010.

KEYNES, J. M. Teoria geral do emprego, do juro e da moeda. Tradutor: Mário Ribeiro da Cruz. São Paulo: Editora Atlas, 1936 [1992].

LANGONI, C.G. Distribuição da Renda e Desenvolvimento Econômico no Brasil. Editora Expressão e Cultura, Rio de Janeiro, 1973.

MALAN, P. S. Distribuição de Renda e Desenvolvimento: novas evidências e uma tentativa de clarificação da controvérsia. In: Dados nำ21, UFMG, MG, 1978.

MEDEIROS, C. A. Industrialização e regime salarial na economia brasileira: os anos 60 e 70. Economia e Sociedade, no 2, UNICAMP, Campinas, 1993.

MORGAN, M. Extreme and Persistent Inequality: New Evidence for Brazil Combining National Accounts, Surveys and Fiscal Data, 2001-2015. WID, world WORKING PAPER SERIES № 2017/12, August, 2017.

OLIVEIRA, F. A Economia Brasileira: crítica da razão dualista. Seleções Cebrap, n.1, São Paulo, 1975.

SABÓIA, J. M. Transformações no mercado de trabalho no Brasil durante a crise: 19801983. Revista de Economia Política, 6(3), São Paulo: Brasiliense, 1986.

SALM, C. Sobre a recente queda da desigualdade de renda no Brasil: uma leitura crítica. In: PAES DE BARROS, R. et al. Desigualdade de Renda no Brasil: Uma análise da queda recente. IPEA, Brasília, 2006.

SERRA, J. A reconcentração da renda: justificações, explicações, dúvidas. In: TOLIPAN, R. e TINELLI, A.C. (orgs.). A controvérsia sobre a distribuição de renda no Brasil. Zahar, Rio de Janeiro, 1978.

SOARES, S. S. D. Distribuição de renda no Brasil de 1976 a 2004 com ênfase no período entre 2001 e 2004. TD 1166. Brasília: IPEA, 2006.

SOUZA, P. H. G. F. A desigualdade vista do topo: a concentração de renda entre os ricos no Brasil, 1926-2013. Tese de Doutorado. Universidade de Brasília, Brasília, 2016.

TROVÃO, C. J. B. M. Desigualdade multidimensional: uma abordagem keynesiana para o seu enfrentamento. Tese de Doutorado em Desenvolvimento Econômico. Unicamp, Campinas, 2015. 


\begin{abstract}
ANEXO
Os indicadores utilizados na análise foram construídos da seguinte forma:

1) Dimensão Mercado de Trabalho e Renda

Taxa de desemprego = Relação entre o total de desocupados e a população economicamente ativa.

Taxa de formalização = Relação entre os ocupados com contribuição à previdência e o total de ocupados

Taxa de assalariamento $=$ Relação entre o número de assalariados (trabalhadores agrícolas, do setor privado, do setor público e empregados domésticos) e o total de ocupados

Incidência do trabalho agrícola = Relação entre o número de famílias com ao menos um membro ocupado no setor agrícola e o total de famílias

Incidência da previdência social = Relação entre o número de famílias com ao menos um membro que tenha recebido algum tipo de remuneração oriunda da previdência social (aposentadoria ou pensão) e o total de famílias

Incidência de programas sociais = Relação entre o número de famílias que recebiam algum tipo de benefício social (renda mínima, bolsa escola, bolsa família, etc.) e o total de famílias
\end{abstract}

Incidência da renda do trabalho = Relação entre o número de famílias com ao menos um membro que tenha exercido trabalho remunerado e o total de famílias

Participação da renda do trabalho na renda total = Relação entre a massa de rendimentos do trabalho e a massa de rendimentos de todas as fontes

2) Dimensão Condições de Vida e Consumo

Densidade de morador por dormitório = Número médio de moradores por cômodo utilizado como dormitório

Densidade de morador por banheiro = Número médio de moradores por banheiro exclusivo ao domicílio

Proporção famílias sem parede apropriada = Relação entre o número de famílias vivendo em domicílios sem parede apropriada (exemplos: taipa, madeira aproveitada, palha ou sem parede) e o total de famílias

Proporção de famílias sem banheiro exclusivo do domicílio = Relação entre o número de famílias vivendo em domicílios sem banheiro de uso exclusivo e o total de famílias Proporção famílias sem rede apropriada de esgoto = Relação entre o número de famílias vivendo em domicílios sem rede apropriada de esgoto (exemplos: fossa rudimentar, vala, rio, lago ou mar) e o total de famílias

Proporção famílias sem água encanada = Relação entre o número de famílias vivendo em domicílios sem água canalizada no domicílio ou na propriedade e o total de famílias Proporção famílias sem coleta lixo apropriada = Relação entre o número de famílias vivendo em domicílios sem coleta de lixo apropriada (exemplos: o lixo é queimado, enterrado, jogado em terreno baldio ou logradouro público, jogado em rio, lago ou mar) e o total de famílias

Proporção famílias sem acesso à energia elétrica = Relação entre o número de famílias vivendo em domicílios sem energia elétrica e o total de famílias

Proporção de famílias sem televisão = Relação entre o número de famílias vivendo em domicílios sem televisão no domicílio e o total de famílias

Proporção de famílias sem máquina de lavar = Relação entre o número de famílias vivendo em domicílios sem máquina de lavar no domicílio e o total de famílias 
Proporção de famílias sem geladeira = Relação entre o número de famílias vivendo em domicílios sem geladeira ou freezer no domicílio e o total de famílias

Proporção de famílias sem telefone (fixo ou celular) = Relação entre o número de famílias vivendo em domicílios sem telefone (fixo ou celular) no domicílio e o total de famílias

Proporção de famílias sem computador = Relação entre o número de famílias vivendo em domicílios sem computador pessoal no domicílio e o total de famílias

Proporção de famílias sem internet no domicílio = Relação entre o número de famílias vivendo em domicílios sem computador pessoal com acesso à internet no domicílio e o total de famílias

Proporção de famílias sem veículo particular = Relação entre o número de famílias vivendo em domicílios sem veículo particular no domicílio e o total de famílias

3) Dimensão Educação

Taxa de analfabetismo = Relação entre o número de pessoas que não sabem ler e escrever e o total de pessoas

Taxa escolarização crianças (6 a 14 anos) = Relação entre o número de crianças de 6 a 14 anos que frequentavam a escola e o total de crianças

Defasagem escolar (6 a 14 anos) = Relação entre o número de crianças de 6 a 14 anos em defasagem escolar (não frequentavam série compatível com a idade) e o total de crianças de 6 a 14 anos

Incidência do ensino médio completo = Relação entre o número de pessoas maiores de 17 anos com ensino médio completo e o total de pessoas de 17 anos ou mais

Incidência do Ensino Superior = Relação entre o número de pessoas maiores de 21 anos com ensino superior completo e o total de pessoas de 21 anos ou mais

4) Dimensão Demografia

Razão de dependência = Relação entre o número de pessoas com menos de 15 e/ou mais de 65 anos e o número de pessoas pertencentes à faixa etária de 15 a 64 anos

Tamanho médio das famílias = Número médio de pessoas por família

Proporção famílias com chefia feminina = Relação entre o número de famílias com chefia feminina e o total de famílias

Proporção de famílias com residência inferior a 4 anos = Relação entre o número de famílias com residência inferior a 4 anos e o total de famílias

Proporção de famílias com chefia de não brancos = Relação entre o número de famílias com chefia de não brancos e o total de famílias

Proporção de domicílios localizados em área rural = Relação entre o número de domicílios localizados em área rural e o total domicílios

Proporção de Domicílios pertencentes à Região Nordeste $=$ Relação entre o número de domicílios pertencentes à Região Nordeste e o total domicílios

5) Dimensão Saúde - Agravantes da Condição Social (indicadores que avaliam a proporção de famílias - \%)

Com uma ou mais pessoas com dificuldade permanente de enxergar = Relação entre 0 número de famílias com uma ou mais pessoas com dificuldade permanente de enxergar e o total de famílias

Com uma ou mais pessoas com dificuldade permanente de ouvir = Relação entre o número de famílias com uma ou mais pessoas com dificuldade permanente de ouvir e o total de famílias 
Com uma ou mais pessoas com dificuldade permanente de caminhar ou subir degraus = Relação entre o número de famílias com uma ou mais pessoas com dificuldade permanente de caminhar ou subir degraus e o total de famílias

Com uma ou mais pessoas com deficiência mental/intelectual permanente $=$ Relação entre o número de famílias com uma ou mais pessoas com deficiência mental/intelectual permanente e o total de famílias

6) Dimensão Discriminação

Diferença dos rendimentos entre mulheres e homens = Relação entre os rendimentos de mulheres e homens

Diferença dos rendimentos entre negros e brancos = Relação entre os rendimentos de negros e brancos

Proporção de crianças negras em defasagem escolar = Relação entre o número de crianças negras de 7 a 14 em defasagem escolar e o total de crianças negras

Proporção de crianças brancas em defasagem escolar = Relação entre o número de crianças brancas de 7 a 14 em defasagem escolar e o total de crianças brancas

Taxa de analfabetismo de negros = Relação entre o número de pessoas negras que não sabem ler e escrever e o total de pessoas negras

Taxa de analfabetismo de brancos = Relação entre o número de pessoas brancas que não sabem ler e escrever e o total de pessoas brancas

\section{NOTAS DE AUTOR}

\section{CONTRIBUIÇÃO DE AUTORIA}

Cassiano José Bezerra Marques Trovão - Concepção. Coleta de dados, Análise de dados, Elaboração do manuscrito, Revisão e aprovação da versão final do trabalho

Juliana Bacelar de Araújo - Elaboração do manuscrito. Análise de dados, Participação ativa da discussão dos resultados, Revisão e aprovação da versão final do trabalho.

\section{FINANCIAMENTO}

Não se aplica.

\section{CONSENTIMENTO DE USO DE IMAGEM}

Não se aplica.

\section{APROVAÇÃO DE COMITÊ DE ÉTICA EM PESQUISA}

Não se aplica.

\section{CONFLITO DE INTERESSES}

Não se aplica.

\section{LICENÇA DE USO}

Este artigo está licenciado sob a Licença Creative Commons CC-BY. Com essa licença você pode compartilhar, adaptar, criar para qualquer fim, desde que atribua a autoria da obra.

\section{HISTÓRICO}

Recebido em: 09-05-2018

Aprovado em: 11-09-2018 